\title{
Sow the wind, reap the whirlwind? Mobilization cascades in direct democratic initiatives.
}

\author{
Marko Kovic* \\ First draft: January 2015 \\ This version: February 2017
}

\begin{abstract}
This paper explores the possibility of mobilization cascades in direct democratic popular initiatives. A mobilization cascade is a salience-based mobilizing effect whereby one popular initiative has a positive mobilizing effect on a subsequent popular initiative that deals with with a similar policy issue. The existence of a mobilization cascade would imply that voters develop salience for and positive attitudes towards policy issues merely through directdemocratic exposure to those policy issues in the recent past. In order to explore the mobilization cascade, I analyze three popular initiative pairs from Switzerland from the years 2012, 2013 and 2014. In each year, two initiatives dealt with similar policy issues, and the second initiative in each pair was making more far-reaching demands. The results suggest that a mobilization cascade might exist, but that it is probably a weak effect.
\end{abstract}

\section{Introduction: Popular initiatives in Switzerland}

Direct democracy is a prominent feature of contemporary national politics all over the world, given the fact that direct democracy is in use in well over 100 countries [1]. Of course, all of these countries do not incorporate direct democracy in a strict sense of truly direct, immediate and perpetual government by the people, which is a task that has been recognized as improbable if not impossible for centuries [2]. Rather, a modern understanding of direct democracy is one of direct democratic procedures that give voters an opportunity to have a say in legislative issues in addition to the "standard" periodic election of representatives [3].

*ZIPAR - Zurich Institute of Public Affairs Research / marko.kovic@zipar.org / +41 76335 0617. 
The one country that stands out in its frequency of use of direct democratic procedures is Switzerland [4]. Direct democracy is present at the municipal, cantonal 1 and federal levels of polity in Switzerland, and it has a profound effect on the logic of political decision-making $\mid 5,6,7,8,9$, . Direct democratic procedures in Switzerland are comprised of mandatory top-down procedures initiated by the executive branch as well as of optional bottom-up procedures that are initiated by anyone who manages to collect a sufficient amount of citizens' signatures. One such bottom-up direct democratic procedure are federal popular initiatives: By collecting 100 '000 valid signatures of Swiss citizens, any interest group or even, in principle at least, any singular citizen can propose a change to the federal constitution and bring that proposal to a national vote. In order to pass, a popular initiative has to receive an overall national majority of yes votes as well as the majority of yes votes in more than half of the 26 cantons.

Figure 1: The number of federal popular initiatives that came to a vote since 1893.

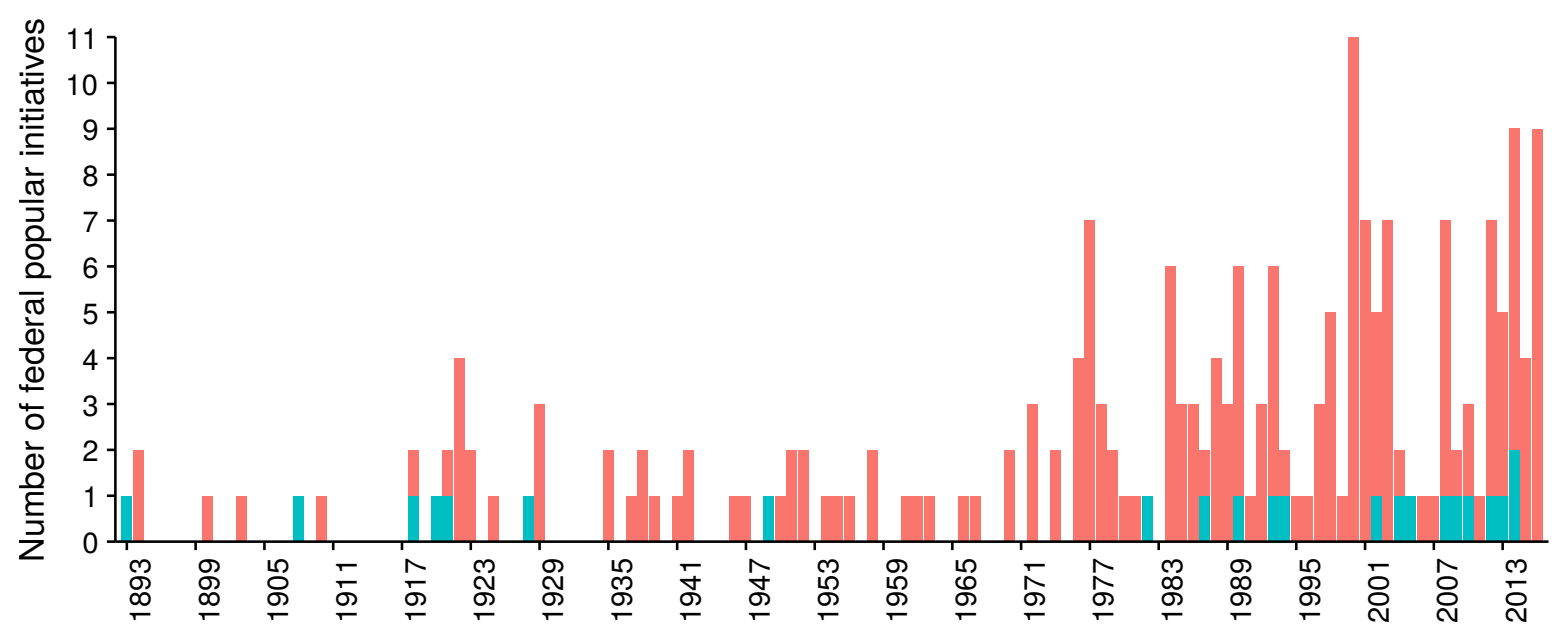

Blue bars represent initiatives that were rejected at the ballot, red bars represent initiatives that passed. Data source: The Swiss Federal Statistical Office.

The use of federal popular initiatives in Switzerland has increased since the 1970-ies, as can be seen in Figure 1. This increase is not random in nature, and popular initiatives are not independent and identically distributed events. The policy issues that are addressed with popular initiatives are not randomly chosen from a theoretical policy space, but they are, metaphorically speaking, products of societal political discourse, of constellations of political actors, and of political windows of opportunity at some points in time. It is not surprising, then, that

\footnotetext{
${ }^{1}$ Swiss cantons are polities very similar to states in the United States.
} 
multiple popular initiatives would tackle similar or the same policy issues in a short period of time, because those issues might be of general interest at those points in time. Such a clustering of popular initiatives took place in Switzerland in the years 2012, 2013 and 2014. In each of those years, there were two federal popular initiatives that dealt with a very similar policy issues. I call these co-occurrences of popular initiatives "initiative pairs".

In three consecutive years, then, the Swiss voted on an initiative pair. Those initiative pairs in the years 2012, 2013 and 2014 weren't only notable because they dealt with similar topics. In each of those initiative pairs and years, the chronologically latter initiative in the initiative pair that came to a vote later in the given year was more far-reaching, or more radical in its demands than the first initiative in the initiative pair. By "radicality", I do not imply any normative evaluation, bit simply the degree of departure from the status quo before both initiatives. Table 1 provides an overview of the initiatives in question.

Table 1: The three pairs of popular initiatives that addressed the same policy issues (per pair).

\begin{tabular}{lllll}
\hline Initiative & Year & Date of the vote & Yes share (\%) & Turnout (\%) \\
\hline Home savings 1 & 2012 & March 11 & 44.2 & 45.1 \\
Home savings 2 & 2012 & June 17 & 31.1 & 38.6 \\
\hline Executive pay & 2013 & March 3 & 68 & 46.7 \\
1 to 12 & 2013 & November 24 & 34.7 & 53.6 \\
\hline Mass immigration & 2014 & February 9 & 50.3 & 56.6 \\
Ecopop & 2014 & November 30 & 25.9 & 49.4 \\
\hline
\end{tabular}

In 2012, two home savings initiatives had almost the identical goal of introducing tax reliefs for homeowners. However, the first initiative only proposed to give cantons the legal competence to introduce tax reliefs, while the second initiative proposed to make tax reliefs for homeowners mandatory on a federal level. In 2013, the "executive pay" initiative proposed to give shareholders of a company a say in the remuneration of the company's executive personnel, with the goal of stopping what was publicly perceived as inappropriately high CEO pay in some public companies. The second initiative in the 2013 initiative pair, the" 1 to 12 " initiative, aimed to introduce a fixed, but relative cap on the remuneration in all companies by limiting the highest salary in a company to, at most, 12 times the lowest salary in that company. In 2013, thus, both initiatives proposed to introduce measures that would limit CEO salaries and bonuses, but the measures proposed by the second initiative were much more immediately tangible. In 2014, both initiatives of interest proposed the introduction of quotas for migrants to Switzerland. However, 
the "mass immigration" initiative only demanded the introduction of quotas in principle, while the second initiative, named "Ecopop" after the organization that created it, proposed a fixed quota of at most $0.2 \%$ yearly population growth by way of immigration.

As can be seen in ??, the second, more radical initiative in each initiative pair was met with much less approval at the ballot than the first initiative in the initiative pair. This observation lends itself to a plausible prima facie interpretation: The median voter is simply more favorable towards less radical proposals. However, a glance at the voter turnouts in ?? confounds this narrative: There is always a sizeable difference in voter turnout between the first and the second initiative of the initiative pairs, and furthermore, there is no immediately obvious relationship between initiative radicality and voter turnout; the second, more radical initiative in an initiative pair does not consistently have either lower or higher turnout than the first initiative.

The goal of this paper is to shed some exploratory and explanatory light on a particular kind of mobilization of one popular initiative on another. More specifically, this paper seeks an answer to the following research question:

- Does voting behavior as turnout at and support for a popular initiative positively impact future voting behavior as turnout at and support for a similar popular initiative?

\section{Direct democracy and voter mobilization}

A number of aspects pertaining to voter mobilization in the context of direct democratic procedures have been analyzed in some detail. Of those aspects, the impact of direct democratic procedures on voter participation in elections has probably been studied most extensively. Early research in the US context has only found scant evidence that the presence of direct democratic procedures in US states boosts election turnout [10, 11]. More recent research, however, indicates that direct democracy might indeed have a positive effect on election turnout [12, 13]. This mobilizing effect in the US is stronger for mid-term elections than for presidential elections [14]. Presidential elections are thought to have a relatively high salience on their own, but in mid-term elections that are, for the most part, shorter in terms of electoral campaigns and less salient, peripheral voters might be mobilized by the presence direct democratic ballot measures [15]. Additionally, there is some evidence that the strength of the mobilizing effect of direct democratic procedures on election turnout is influenced not only by the frequency of direct democratic ballot measures, but also by the campaign intensity for specific ballot measures [16, 17]. Newer findings for the state-level context in the USA, thus, somewhat 
consistently show that direct democracy increases election turnout. The same cannot be said for Switzerland: Research has found an effect of direct democracy on electoral participation neither for national $[18]$ nor for cantonal elections 19 , 20 .

For the present study, another, less thoroughly studied aspect of voter mobilization in the context of direct democracy is more relevant than direct democracy's effects on election turnout: The factors that mobilize voters to participate in direct democratic ballot measures themselves. When it comes to elections, it is a well-established reality of political life that most voters do not approach the ideal of fully informed citizens. Instead, voters rely on information cues and shortcuts in order to arrive at voting decisions [21, 22]. It is, therefore, plausible that the use of heuristics should also extend to voting behavior in direct democratic procedures. After all, the reliance on heuristics in addition to deliberate, rational reasoning is almost certainly not limited to some specific domains of politics, but rather a general trait of human cognition [23, 24]. Direct democratic voting behavior has been shown to be influenced by heuristics such as knowledge about the general stance of political actors [25]. In a broader sense, this finding holds true for Switzerland [26] as well as for the US [17]: Partisan cues matter for voting behavior. Voters' preferences, in this sense, will often take the form of "gut feelings", whereby the political decision-making that is voting will not be based on any sort of rational analysis of the issue at hand, but rather be a quasi-automatic response to cues.

If one, then, accepts that decision-making by voters is not a purely rational expression of preferences, but also influenced by cognitive biases, and if one accepts, furthermore, that this general nature of cognition in the realm of politics extends to voting behavior in the context of direct democratic procedures, what sort of theoretical assumptions, then, are appropriate and plausible in order to find an answer to this study's research question? I make two core presuppositions:

- Presupposition 1: There is such a thing as rational-choice voting. Voters have preferences about direct democratic initiatives, and they tend to vote rationally in the sense that they tend to vote according to their rational preferences.

- Presupposition 2: Voting in the context of direct democratic initiative pairs is not purely rational, but it is affected by a specific class of cognitive heuristics that result in salience-based mobilization. These heuristics tend to impact voter preferences in that they impact whether people vote as well as how people vote on the second initiative in an initiative pair.

These two presuppositions are not at all extraordinary in light of the available research. It has been demonstrated that what mobilizes people in direct democratic 
procedures is, to a degree, the mere awareness of a ballot measure [27] and the subjective allocation of importance to an issue addressed by the ballot measure [28]. These empirical examples are indicative of the specific class of cognitive heuristics that is posited in the second of my two presuppositions. Salience, of course, is a neutral expression that simply describes that something is relatively more prominent in some sense than something else, given that awareness is a zero-sum game. In a more particular cognitive sense, the origin of salience is interesting, because it can be irrational in nature. There are two strong heuristics that have an impact on salience genesis. The first one is the availability heuristic [29]: In inferences, judgments and decision-making, we are heavily influenced by examples and experiences we can recall. If we have experienced something before, that experience will influence how we think about the class of phenomena associated with that experience - no matter how anecdotal and unrepresentative that experience is. The second heuristic that leads to irrational salience is mere exposure [30]: Not only does being exposed to an issue or object change our allocation of importance to that object, but it also changes our attitudes towards that object - merely by being exposed to something, we become more accepting of it.

Conceptually, then, I imagine voters to be, in principle, rational voters who are affected by cognitive heuristics. In the context of direct democratic initiative pairs, this general model of voter behavior translates into a specific expectation: Merely by taking place, the first initiative in an initiative pair builds up (irrational) salience for a specific issue. That salience carries over into the second initiative in an initiative pair, and it becomes manifest in the form of a mobilizing effect both in terms of turnout and support. I call this type of salience-based mobilization a mobilization cascade.

Unsurprisingly, the idea of salience-based mobilization in direct democratic procedures is not completely new. Salience-based mobilization has mainly been observed for political topics that have to do with moral questions. One specific issue that stands out in this context of salience-based mobilization is that of gay rights 31, 32. This kind of salience-based mobilization for ballot measures has also been proposed as a possible mobilization mechanism in elections [33, 34]: Mobilization for a ballot measure based on issue salience spills over into electoral participation. The concept of the mobilization cascade as introduced above, however, has not yet been formulated and put to the empirical test.

\subsection{Assumptions about the mobilization cascade}

In the previous section, I have described mobilization cascades in the context of direct democratic initiatives as a specific form of salience-based mobilization that consists of two aspects: The genesis of salience as positive turnout mobilization through the availability heuristic, and the genesis of positive attitude mobilization 
through mere exposure. These two dimensions imply a set of empirical conditions that should be observable if the mobilization cascade was real.

First, one would expect that the probability to vote yes in the first initiative in an initiative pair has a positive impact on the probability to vote yes in the second initiative. Second, one would expect that the probability to vote at all in the first initiative has a positive effect on the probability to vote at all in the second initiative. Third, one would also expect that the probability to vote yes in the first initiative has a positive effect the probability to vote at all in the second initiative. Fourth, one would expect that the probability to vote at all in the first initiative has a positive effect on the probability to vote yes in the second initiative.

These four conditions are, of course, only logical consequences of a mobilization cascade as the interplay between the availability heuristic that primarily affects turnout and the mere exposure heuristic that primarily affects attitudes in the sense of support. To these four expected conditions, we can add a fifth one: The Simpson's paradox [35] should not exist. When data is analyzed on the lowest available level, it is possible to observe patterns in the data that actually disappear when the real-world multilevel structure of the data is taken into account. This means that a mobilization cascade should be observable when the data is analyzed with information of groups included in the analysis. In the present context, this multilevel, or grouping structure takes the form of cantons? 2 .

The empirical goal of this paper is to explore these five assumptions in the context of three initiative pairs from 2012, 2013 and 2014 that are summarized in Table 1.

\section{Data and methods}

\subsection{Data}

The data used in this study is provided by the Swiss Federal Statistical Office. The specific variables that are subjected to analysis are summarized in Table 2.

The data presented in Table 2 is on the municipal level. This means that I do not have data on individual voting behavior. Instead, I work with municipal-level data which is an aggregation of individual votes. The benefit of municipal-level data is that the probability to vote yes, as discussed in subsection 2.1, can be directly operationalized as the yes share in a given municipality. Likewise, the probability to vote at all can be operationalized as the turnout in a given municipality.

The variable "yes share t1" stands for the yes share for the first initiative in an initiative pair, and, accordingly, the variable "yes share t2" stands for the yes share for the second initiative in an initiative pair. I have introduced an additional

\footnotetext{
${ }^{2}$ Swiss cantons are similar federal polities as states in the United States.
} 
Table 2: Variables used in the analyses.

\begin{tabular}{llll}
\hline Variable & Year & mean & SD \\
\hline Yes share t1 & 2012 & 0.47 & 0.09 \\
Yes share t1 & 2013 & 0.69 & 0.07 \\
Yes share t1 & 2014 & 0.55 & 0.11 \\
\hline Yes share t2 & 2012 & 0.33 & 0.09 \\
Yes share t2 & 2013 & 0.34 & 0.08 \\
Yes share t2 & 2014 & 0.28 & 0.09 \\
\hline Turnout t1 & 2012 & 0.46 & 0.10 \\
Turnout t1 & 2013 & 0.49 & 0.10 \\
Turnout t1 & 2014 & 0.58 & 0.07 \\
\hline Turnout t2 & 2012 & 0.37 & 0.09 \\
Turnout t2 & 2013 & 0.56 & 0.08 \\
Turnout t2 & 2014 & 0.50 & 0.08 \\
\hline Municipality size & 2012 & 2055.0 & 6487.6 \\
Municipality size & 2013 & 2151.5 & 6651.4 \\
Municipality size & 2014 & 2194.1 & 6713.6 \\
\hline Canton & $2012-2014$ & - & - \\
\hline
\end{tabular}

variable: municipality size. Municipality size should be included in the analysis because there is evidence that the dynamics of political mobilization may be influenced by community size [36, 37, 38]. Swiss municipalities vary quite a bit in size, so including municipality size as an additional variable should capture those effects, were they to play a role in the mobilization cascade.

Since the variable for municipality size is on a vastly different scale than the other variables, as can be seen in Table 2, I have standardized all predictor variables for the modeling phase. This means that the variables municipality size, yes share at $\mathrm{t} 1$, and turnout at $\mathrm{t} 1$ are transformed so that they have mean 0 and standard deviation 1 . The variables yes share at t2 and turnout at t2 only serve as response variables, and I have left them on their original scale.

The data that I use covers all municipalities in Switzerland. However, the number of municipalities is not the same for every year, and for some of the years, the number of municipalities is different for the first and for the second initiative. That is a consequence of municipal fusions: A number of municipalities in the Italian speaking part of Switzerland, which consists almost exclusively of the canton Ticino, have fused between 2012 to 2014. In 2012 and 2013, the number of municipalities was higher at the first initiative than at the second one. Rather than excluding those municipalities and the municipalities they fused into from 
the dataset, I manually adjusted the original data to create the new post-fusion municipalities in the datasets for the first initiative. In this manner, no information was lost from the dataset. The numbers of municipalities at each point in time are summarized in Table 3,

Table 3: Number of municipalities per year.

\begin{tabular}{llll}
\hline Initiative & Year & $\mathrm{n}$ municipalities & $\mathrm{n}$ municipalities, adjusted \\
\hline$\#$ 1 (Home savings 1) & 2012 & 2484 & 2474 \\
$\#$ 2 (Home savings 2) & 2012 & 2474 & 2474 \\
\hline$\# 1$ (Executive pay) & 2013 & 2397 & 2385 \\
$\#$ 2 (1 to 12) & 2013 & 2385 & 2385 \\
\hline$\#$ 1 (Mass immigration) & 2014 & 2342 & 2342 \\
$\#$ 2 (Ecopop) & 2014 & 2342 & 2342 \\
\hline
\end{tabular}

\subsection{Methods}

From a methodological standpoint, I conduct three analytical steps. In the first analytical step, I estimate a number of regression models that estimate the assumptions one to four, as presented in subsection 2.1. More precisely, I estimate two kinds of models for each initiative pair. One kind of model is the model where the yes share at $\mathrm{t} 2$ is the response variable, and the yes share at $t 1$, turnout at t1 and size. The second kind of model is the model where turnout at t2 is the response variable, and yes share at t1, turnout at t1 and size are the predictors. For each initiative pair, I estimate these models twice: Once as simple single-level linear models, and once as varying intercepts linear models. For the multilevel models, I use cantons as the grouping variables. I do this in order to compare the single-level to the multilevel models; according to assumption five as described in subsection 2.1, the multilevel models should perform at least as well as the single-level models.

In total, then, I estimate twelve models. The twelve models are summarized in Table 4,

I estimate both the single-level and the multilevel models as linear Bayesian regressions. The single-level models take the following form:

$$
\begin{gathered}
y \sim \mathcal{N}(\mu, \sigma) \\
\mu=\alpha+\beta x \\
\alpha \sim \mathcal{N}(0,1)
\end{gathered}
$$


Table 4: The twelve models that are estimated.

\begin{tabular}{llll}
\hline Year & Response variable & Predictor variables & Group-level variable \\
\hline 2012 & yes share $\mathrm{t} 2$ & yes share $\mathrm{t} 1+$ turnout $\mathrm{t} 1+$ size & - \\
2012 & yes share $\mathrm{t} 2$ & yes share $\mathrm{t} 1+$ turnout $\mathrm{t} 1+$ size & canton \\
\hline 2013 & yes share $\mathrm{t} 2$ & yes share $\mathrm{t} 1+$ turnout $\mathrm{t} 1+$ size & - \\
2013 & yes share $\mathrm{t} 2$ & yes share $\mathrm{t} 1+$ turnout $\mathrm{t} 1+$ size & canton \\
\hline 2014 & yes share $\mathrm{t} 2$ & yes share $\mathrm{t} 1+$ turnout $\mathrm{t} 1+$ size & - \\
2014 & yes share $\mathrm{t} 2$ & yes share $\mathrm{t} 1+$ turnout $\mathrm{t} 1+$ size & canton \\
\hline 2012 & turnout $\mathrm{t} 2$ & yes share $\mathrm{t} 1+$ turnout $\mathrm{t} 1+$ size & - \\
2012 & turnout $\mathrm{t} 2$ & yes share $\mathrm{t} 1+$ turnout $\mathrm{t} 1+$ size & canton \\
\hline 2013 & turnout $\mathrm{t} 2$ & yes share $\mathrm{t} 1+$ turnout $\mathrm{t} 1+$ size & - \\
2013 & turnout $\mathrm{t} 2$ & yes share $\mathrm{t} 1+$ turnout $\mathrm{t} 1+$ size & canton \\
\hline 2014 & turnout $\mathrm{t} 2$ & yes share $\mathrm{t} 1+$ turnout $\mathrm{t} 1+$ size & - \\
2014 & turnout $\mathrm{t} 2$ & yes share $\mathrm{t} 1+$ turnout $\mathrm{t} 1+$ size & canton \\
\hline
\end{tabular}

$$
\begin{gathered}
\beta \sim \mathcal{N}(0,1) \\
\sigma \sim \operatorname{Cauchy}(0,2.5)
\end{gathered}
$$

The priors for the intercept $\alpha$ as well as for the coefficients $\beta$ are only vaguely informative with mean 0 and standard deviation 1 . Such a specification is sufficient, because the predictor variables in the models have a range from 0 to 1 . Using broader priors, for example with mean 0 and standard deviation 1000, would not make a lot of sense, obviously. For the top-level scale parameter $\sigma$, I use a half-Cauchy prior $[39 \mid$ with location 0 and scale 2.5 .

The multilevel models are almost identical to the single-level models, with the exception of the introduction of group-level intercepts. The multilevel models take the following form:

$$
\begin{gathered}
y_{i, j} \sim \mathcal{N}\left(\mu_{i, j}, \sigma\right) \\
\mu_{i, j}=\alpha_{i, j}+\beta_{i} x_{i} \\
\alpha_{i, j} \sim \mathcal{N}\left(\alpha_{i}, \tau\right) \\
\alpha_{i} \sim \mathcal{N}(0,1) \\
\tau \sim \operatorname{Cauchy}(0,2.5) \\
\beta_{i} \sim \mathcal{N}(0,1) \\
\sigma \sim \operatorname{Cauchy}(0,2.5)
\end{gathered}
$$


In this formal description of the multilevel models, I specify the group-level intercepts as $\alpha_{i, j}$, where $j$ denotes the group-level of the cantons, and $i$ denotes the population-level intercepts.

I have estimated the models with the computational software Stan [40], called from within the $\mathrm{R}$ environment [41]. In order to perform the estimations, I have used 300 warmup iterations and 600 sampling iterations for each model for three sampling chains. Despite the low number of iterations, all models have successfully converged; no parameter estimate has a potential scale-reduction factor greater than 1.01, which is indicative of successful convergence [42].

In the second analytical step, I determine whether the single-level models or the multilevel models perform better. To that end, I do two things. First, I visually compare posterior predictive checks $[43]$ for the single-level and the multilevel models. The idea of posterior predictive checks is simple: If we believe that a model fits the data well, then that model should be able to generate data that approximates the real, observed data well. For each model, I have generated 200 simulated replications that I compare to the original, observed data. Second, I compare the leave-one-out cross-validation information criterion (LOOIC) and the widely applicable information criterion (WAIC) [44] for the single-level and multilevel models. The LOOIC and WAIC are indications for the out-of-sample predictive performance of models. When used together, the posterior predictive checks and the LOOIC and WAIC should show whether the single-level or the multilevel models perform better. The results of this second analytical step will clarify whether assumption five as described in subsection 2.1 is supported.

In the third and final analytical step, I examine the parameter estimates for the models that have "survived" the previous analytical step of model comparison. The examination of the estimates will clarify whether assumptions one to four as described in subsection 2.1 are supported.

\section{Results}

\subsection{Single-level vs. multilevel models for the 2012 initiative pair}

The posterior predictive checks for the 2012 single-level and multilevel models with yes share at $\mathrm{t} 2$ as the response variable are depicted in Figure 2.

As can be seein in Figure 2, both the single-level and the multilevel model do a decent of simulation replicated data for the response variable, the yes share at $t 2$. But it's visible that the multilevel model is doing a better job, since the simulated replications come closer to the real, observed data in the area of highest density. The LOOIC for the single-level model is -6466.744 , while it is -7072.606 for the 
Figure 2: Posterior-predictive checks for the 2012 models with yes share at t2 as the response variable.
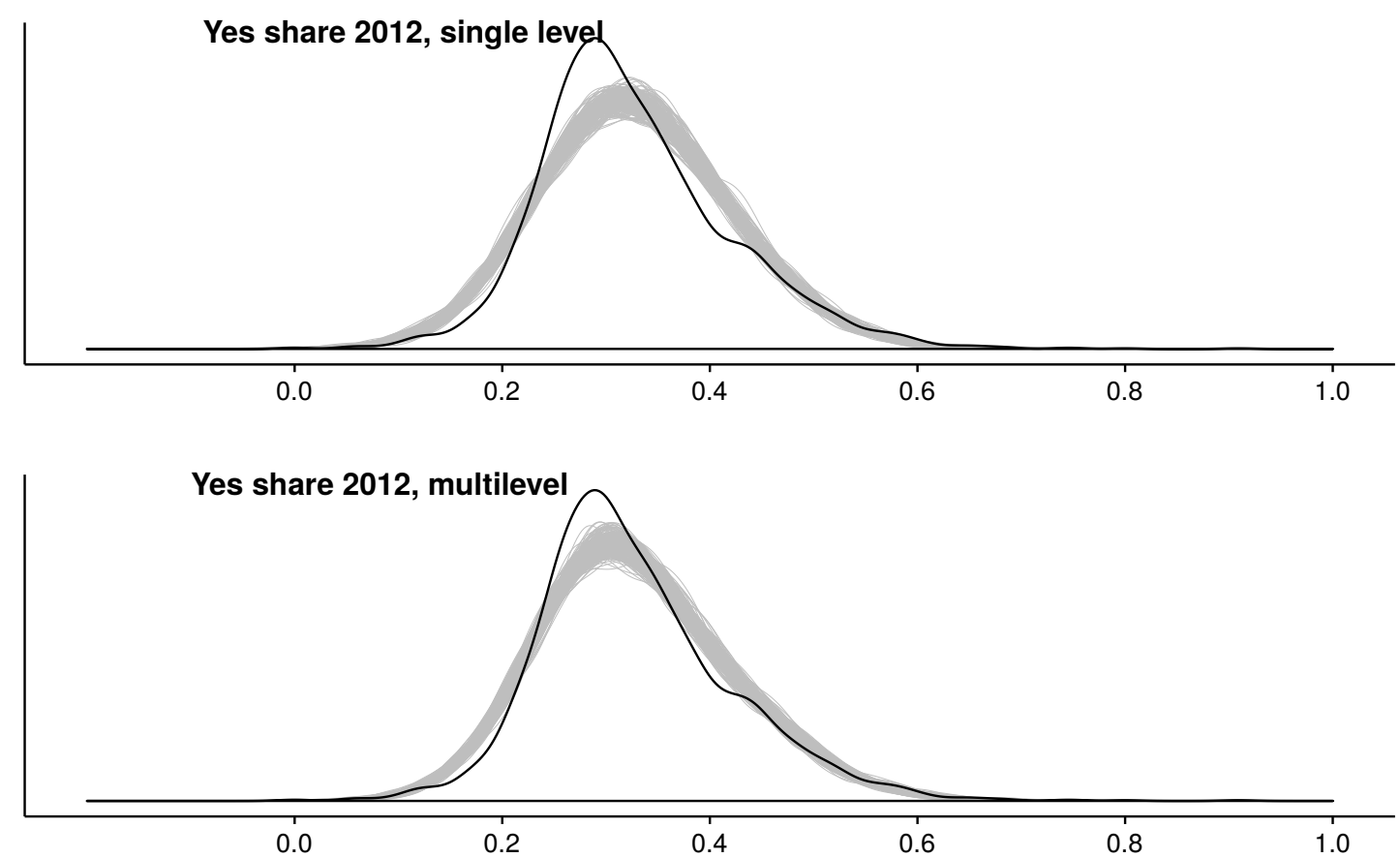

The black line is the observed, real distribution. The gray lines are 200 simulated replications.

multilevel model. Very similarly, the single-level model WAIC is -6466.876, and it is -7072.959 for the multilevel model. It's safe to assume that the multilevel model is outperforming the single-level model on all accounts.

The posterior predictive checks for the 2012 models with turnout at t2 as the response variable are depicted in Figure 3.

Both models produce quite good simulated replications, but both fail to reproduce the slight bimodal tendency in the area of highest density of the real data. The multilevel model is doing a slightly better job in that particular part of the distribution. The LOOIC for the single-level model is -6702.481 , and that for the multilevel model is -7744.04 . Similarly, the single-level model WAIC is -6704.013 , while that of the multilevel model is -7745.43 . Again, the multilevel model is outperforming the single-level model, although the results for the out-of-sample predictive performance as approxiated by LOOIC and WAIC give a clearer picture than the posterior predictive checks. 
Figure 3: Posterior-predictive checks for the 2012 models with turnout at t2 as the response variable.
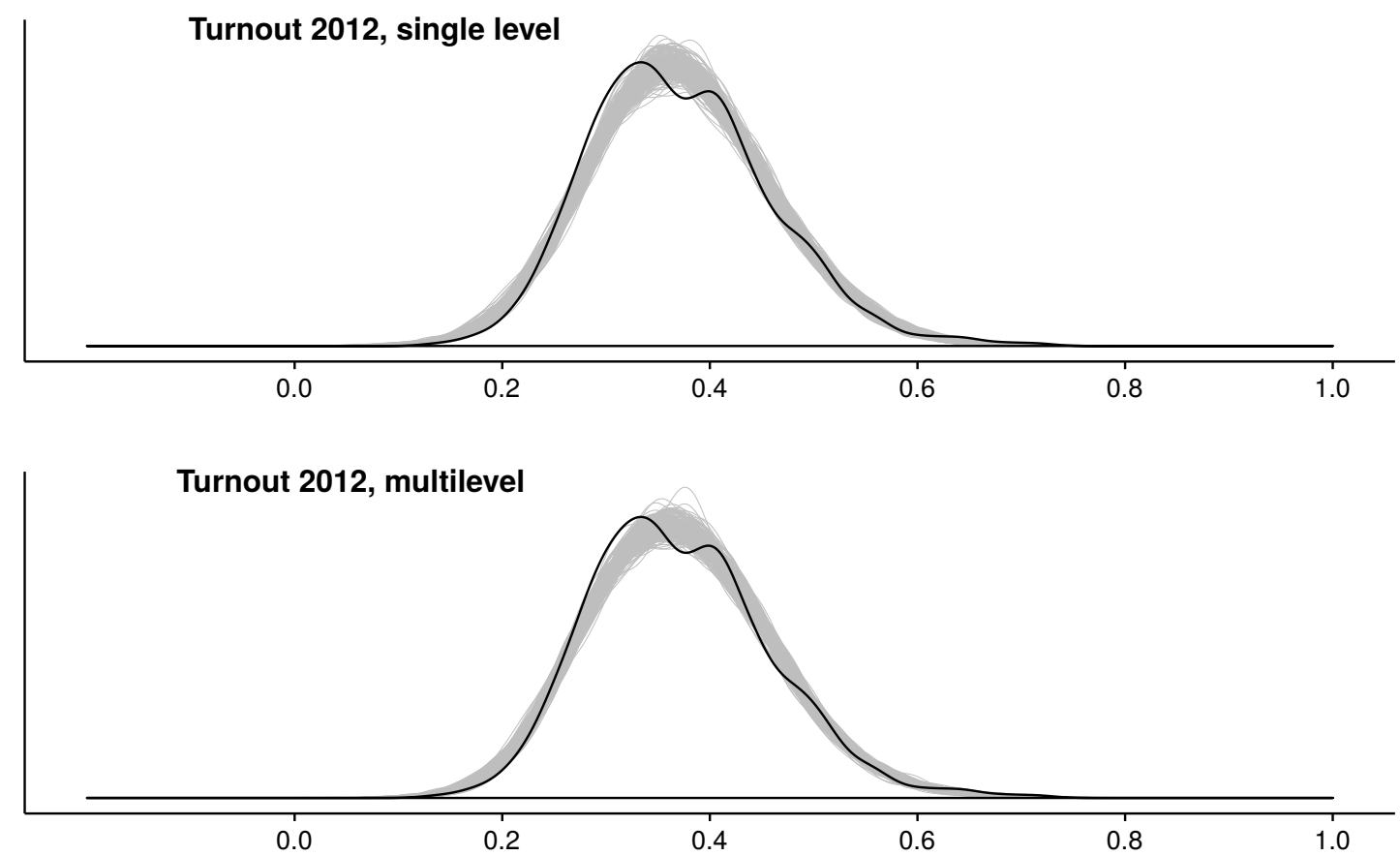

The black line is the observed, real distribution. The gray lines are 200 simulated replications.

Overall, then, the multilevel models outperform the single-level models for the 2012 initiative pairs.

\subsection{Single-level vs. multilevel models for the 2013 initiative pair}

The posterior predictive checks for the 2013 single-level and multilevel models with yes share at $\mathrm{t} 2$ as the response variable are depicted in Figure 4.

The simulated replications generated with the multilevel model are clearly approximating the real data better than the simulated replications of the singlelevel model. The LOOIC for the single-level model is -5705.728 , while that for the multilevel model is -7157.067 . Similarly, the WAIC for the single-level model is -5705.87 , and that for the multilevel model is -7157.816 . The multilevel model easily outperforms the single-level model on all accounts. 
Figure 4: Posterior-predictive checks for the 2013 models with yes share at t2 as the response variable.
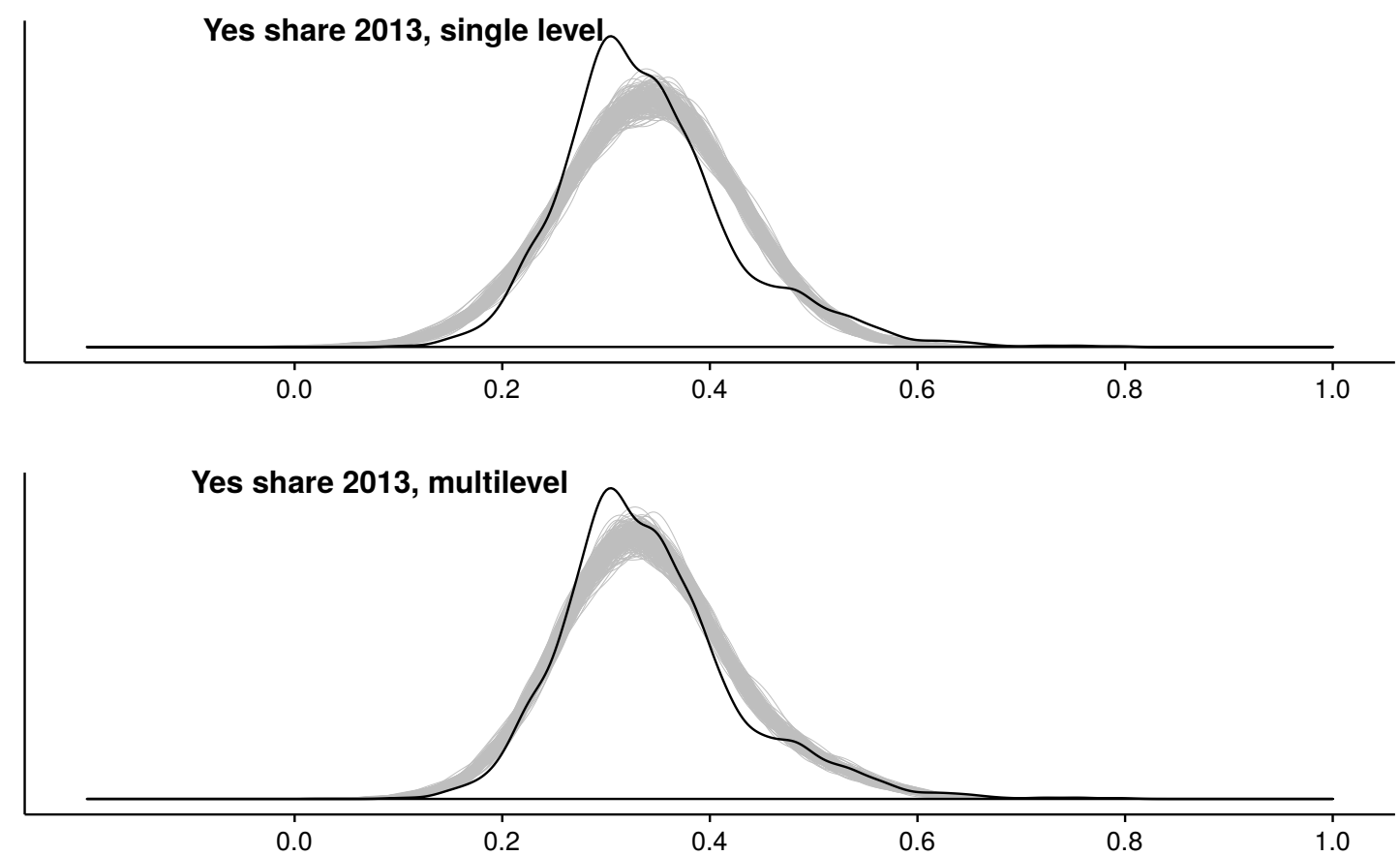

The black line is the observed, real distribution. The gray lines are 200 simulated replications.

The posterior predictive checks for the 2013 single-level and multilevel models with turnout at $\mathrm{t} 2$ as the response variable are depicted in Figure 5.

Both the single-level and the multilevel model are doing a good job, and there is not much difference between them. The multilevel model is handling the are of highest density slightly better than the single-level model. However, in terms of their out-of-sample predictive performance, the difference is stronger. The LOOIC for the single-level model is -6093.16 , and that for the multilevel model is -7283.506 . Similarly, the WAIC for the single-level model is -6093.636 , and that for the multilevel model is -7284.415 .

Overall, the multilevel models for the 2013 initiative pairs outperform the single-level models, as they do for the 2012 models. 
Figure 5: Posterior-predictive checks for the 2013 models with turnout at t2 as the response variable.
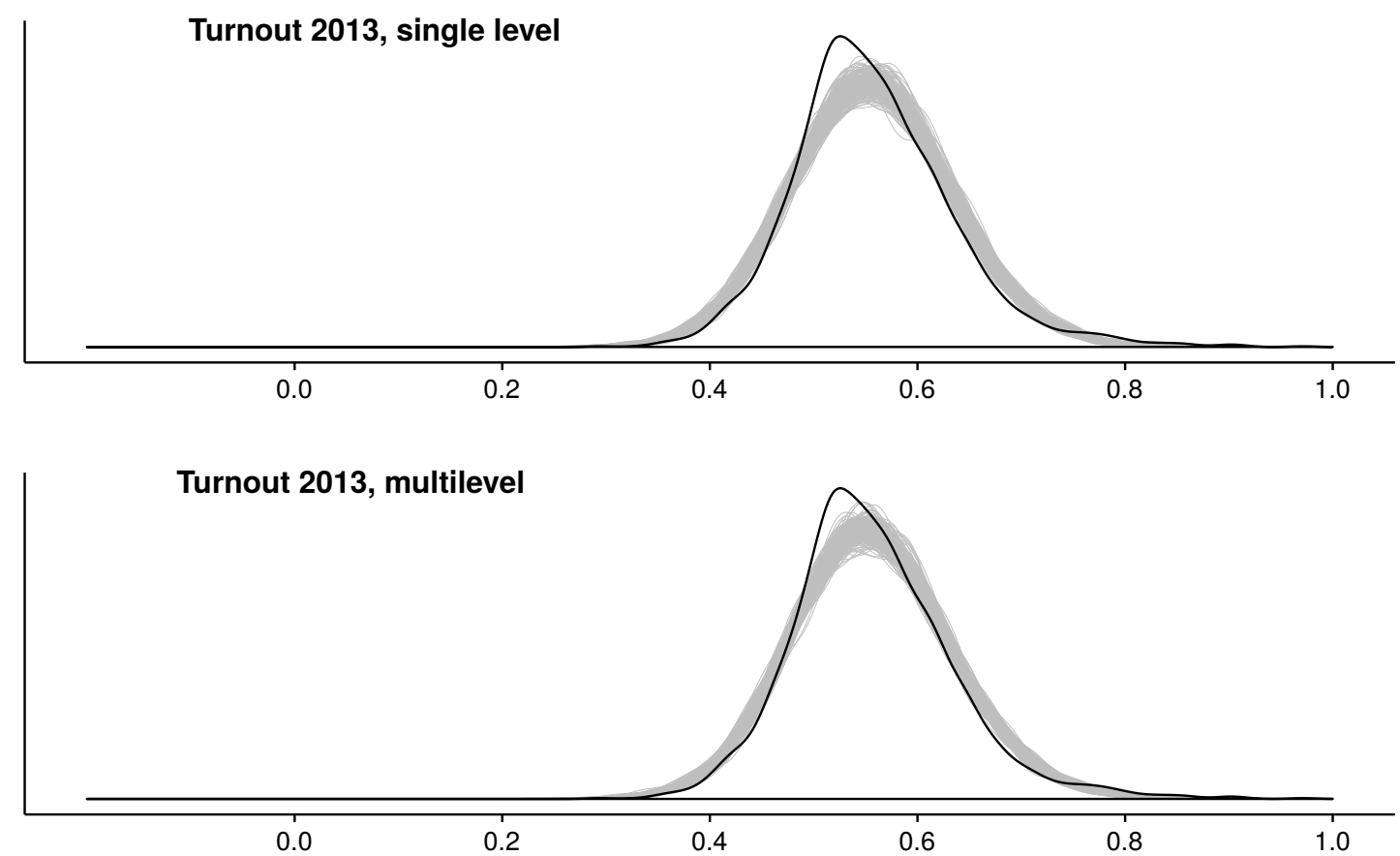

The black line is the observed, real distribution. The gray lines are 200 simulated replications.

\subsection{Single-level vs. multilevel models for the 2014 initiative pair}

The posterior predictive checks for the 2014 single-level and multilevel models with yes share at $\mathrm{t} 2$ as the response variable are depicted in Figure 6.

Both models do a relatively good job with the simulated replications. However, the multilevel is once again doing a little bit better in the are of highest density. The difference between the models is a bit clearer in terms of LOOIC ( -7435.20 vs. $-7806.95)$ and WAIC (-7436.09 vs. -7807.10), where, once again, the multilevel model outperforms the single-level model.

The posterior predictive checks for the 2014 single-level and multilevel models with turnout at t2 as the response variable are depicted in Figure 5.

The two models both do a good job, and the differences between the two are not very strong. The multilevel model is doing once again doing slightly better in 
Figure 6: Posterior-predictive checks for the 2014 models with yes share at t2 as the response variable.
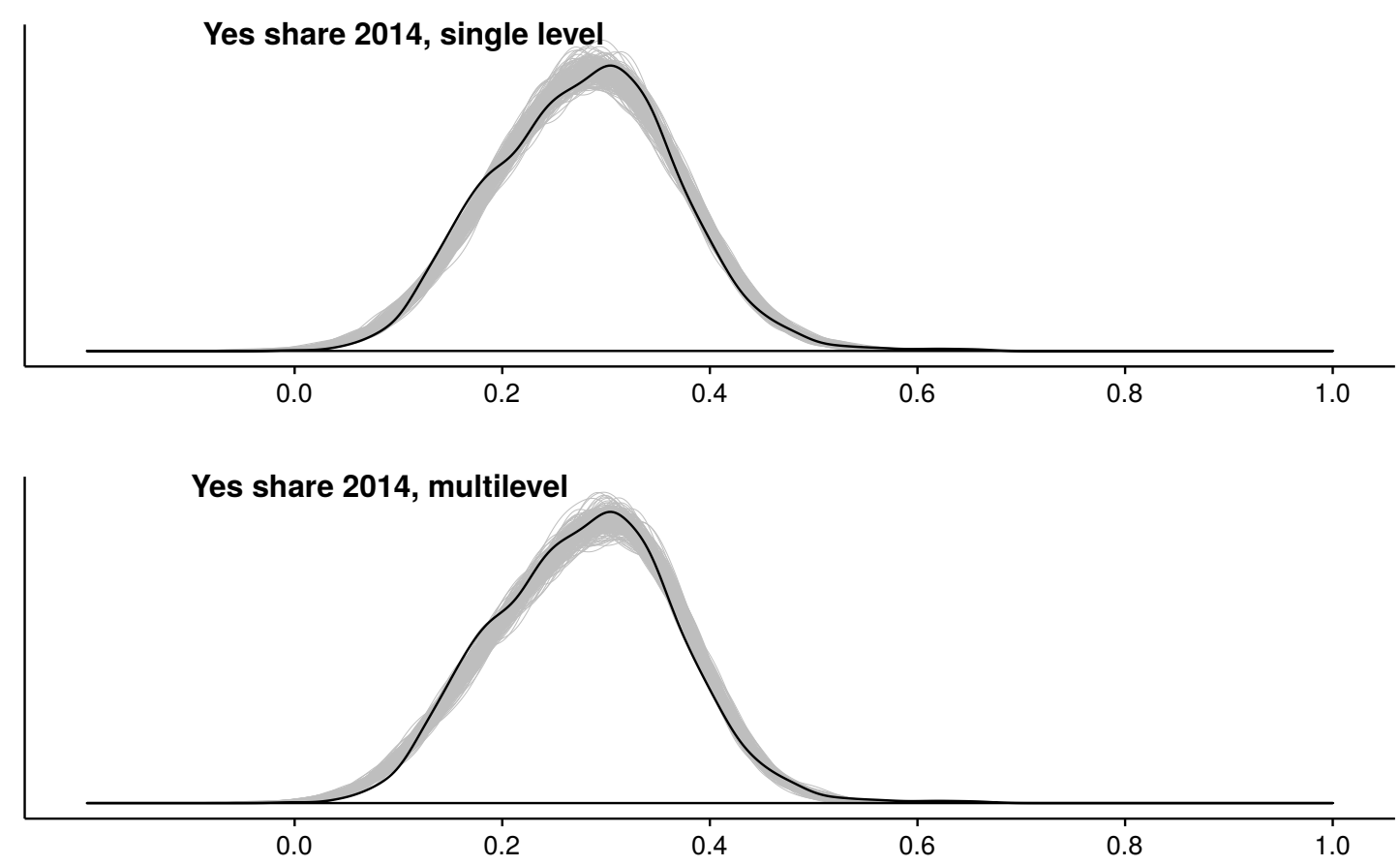

The black line is the observed, real distribution. The gray lines are 200 simulated replications.

the area of highest density. In terms of expected predictive performance, however, the difference between the models is greater. The multilevel model outperforms the single-level model both in terms of LOOIC (-7712.25 vs. -7359.84$)$ and in terms of WAIC ( -7711.16 vs. -7359.99$)$.

Overall, in the 2014 initiative pair, the multilevel models outperform the singlelevel models, just as they do in the 2012 and 2013 initiative pairs.

\subsection{Parameter estimates for the 2012 initiative pair}

In subsection 4.1, we have seen that the the multilevel models outperform the singlelevel models. In this subsection, the parameter estimates for the 2012 multilevel models are presented. First, the estimates for the 2012 multilevel model with yes at $\mathrm{t} 2$ as the response variable are summarized in Figure 8.

The densities represent the posterior probabilities of the parameter estimates, 
Figure 7: Posterior-predictive checks for the 2014 models with turnout at t2 as the response variable.
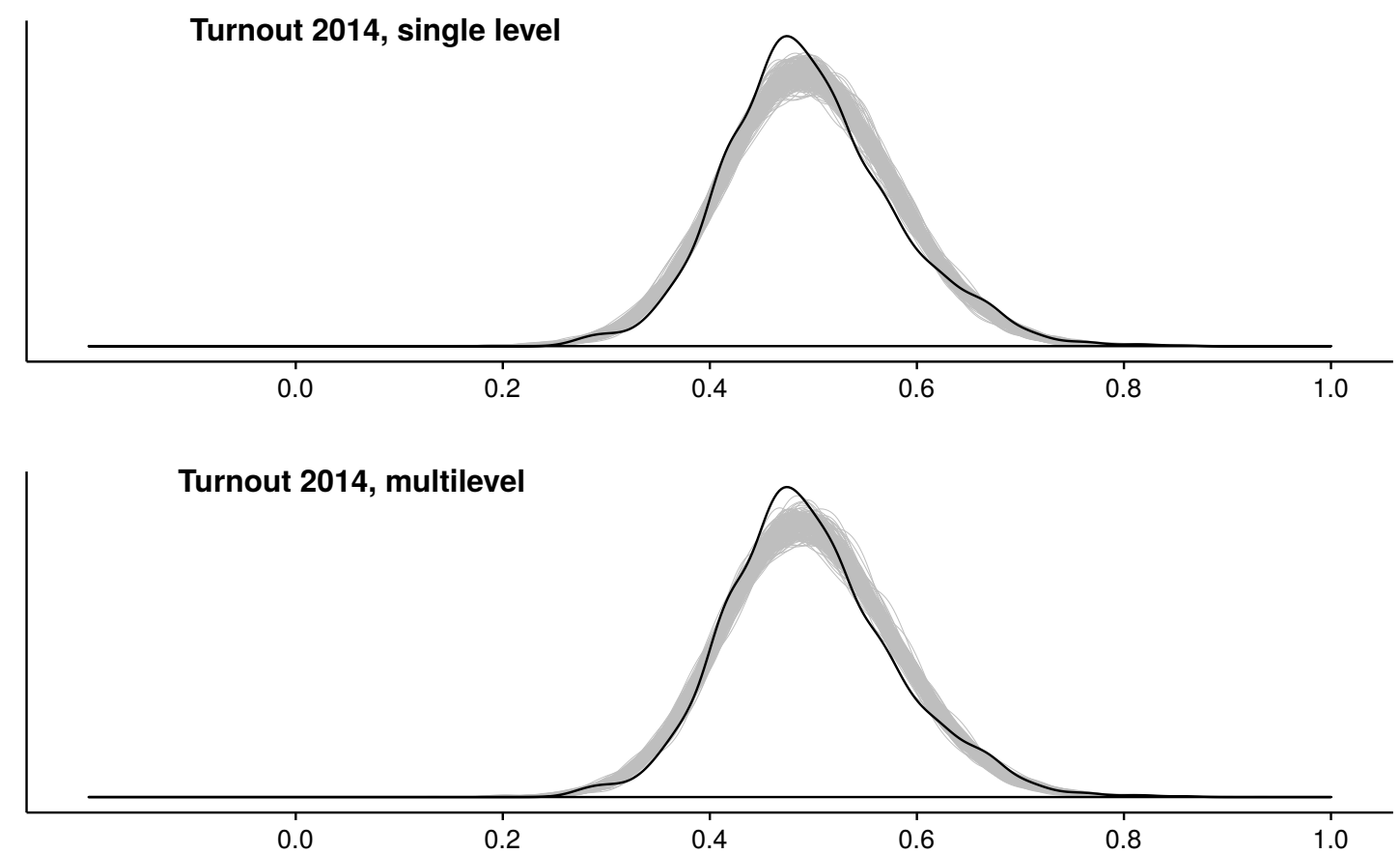

The black line is the observed, real distribution. The gray lines are 200 simulated replications.

given the data and the model. Yes share at t1 has a positive effect of around 0.05. This means that an increase in one standard deviation of yes share at t1, 0.09, results in an average increase of around 0.05. This is a strong effect. Interestingly, turnout at t1 has a very small negative effect, of around -0.004. However, given that most of the posterior distribution lies below 0 , that effect does seem to be more than noise. Finally, municipality size also has a small negative effect, of around -0.003 per one change in municipality standard deviation.

The estimates for the 2012 multilevel model with turnout at t2 as the response variable are presented in Figure 9.

Yes share at t1 has, again, a small negative effect of around -0.008 on average. This means that one increase in sd for yes share at $t 1,0.09$, results in a slightly lower turnout at $\mathrm{t} 2$. Turnout at $\mathrm{t} 1$, in contrast, exhibits a positive and strong effect on turnout at t 2 of around 0.057 per one standard deviation increase of turnout at t1, 0.10. Finally, municipality size has a small positive effect on turnout at t2. 
Figure 8: Parameter estimates for the 2012 multilevel model with yes share at t2 as the response variable.
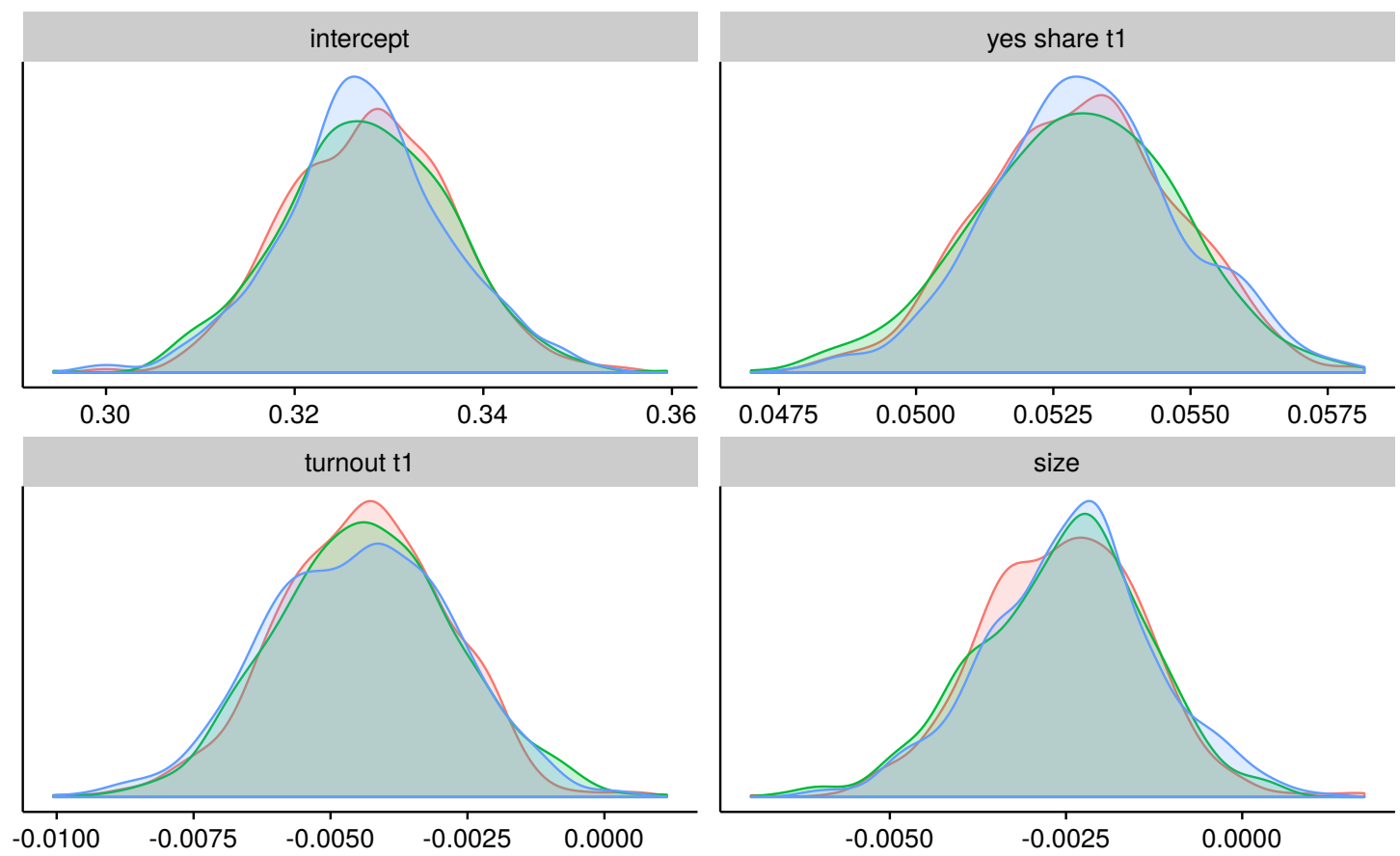

The different colors represent the three sampling chains.

For the 2012 multilevel models, in summary, some unexpected negative effects are observable. Greater turnout at t1 leads to slightly lower yes share at t1. Similarly, greater yes share at $\mathrm{t} 1$ leads to lower turnout at t2.

\subsection{Parameter estimates for the 2013 initiative pair}

Since the better performing models for the 2013 initiative pair were both multilevel models, the estimates for the two 2013 multilevel models are prestented here. First, the estimates for the 2013 multilevel model with yes share at $\mathrm{t} 2$ as the response variable are summarized in Figure 10.

There is a similar pattern of effects as for the 2012 multilevel model with yes share at $\mathrm{t} 2$ as the response variable. Yes share at $\mathrm{t} 1$ has a relatively strong positive effect; on average, one standard deviation increase in yes share at t1, 0.07, results in an increase of 0.037 for yes share at t2. However, turnout at t 1 has a small negative effect on yes share at $\mathrm{t} 1$ of around -0.011 , on average. Municipality size 
Figure 9: Parameter estimates for the 2012 multilevel model with turnout at t2 as the response variable.
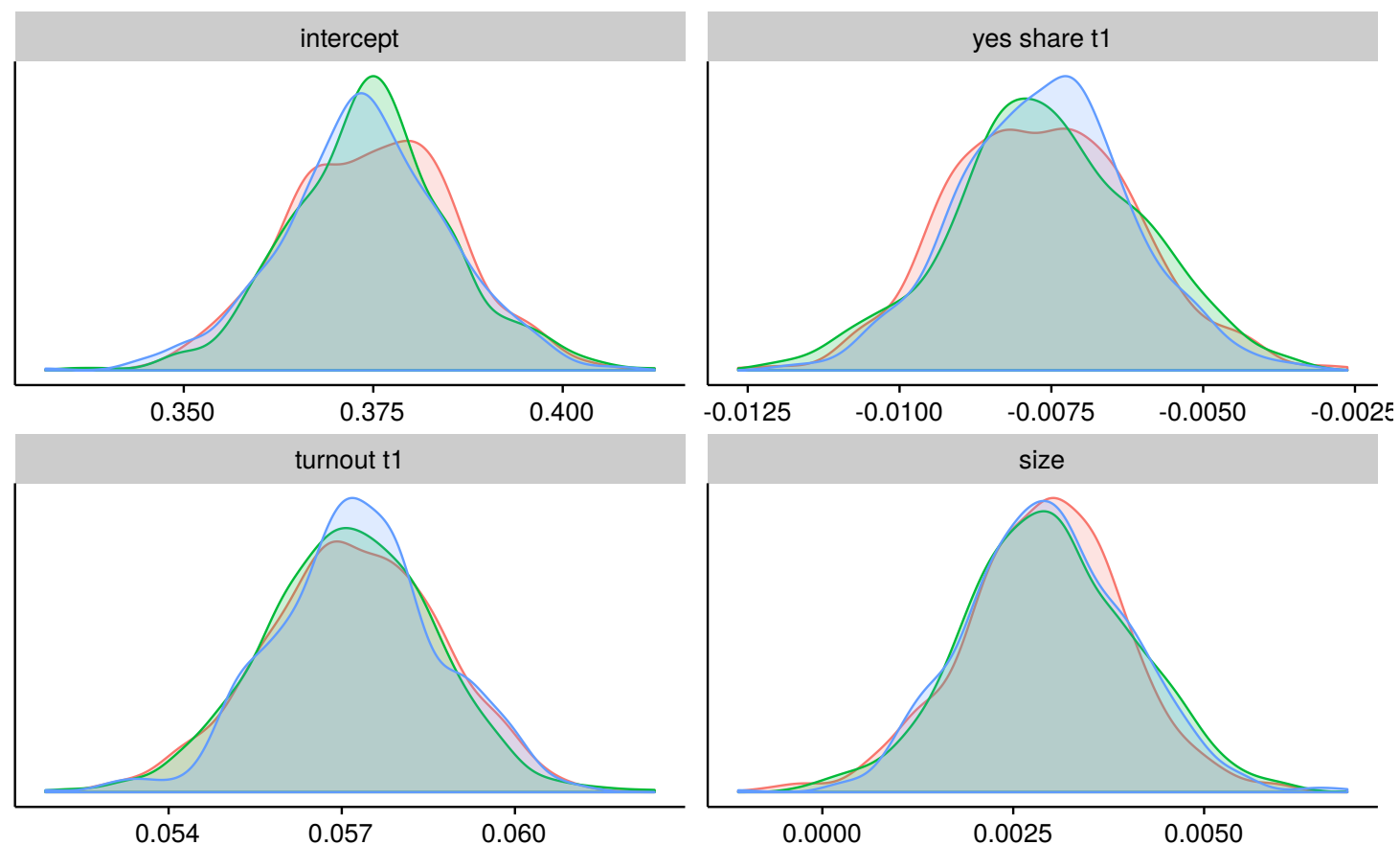

The different colors represent the three sampling chains.

has a small effect, but this time, it is positive and not negative, as with the 2012 model with yes share as the response variable.

The estimates for the 2013 multilevel model with turnout at t2 as the response variable are summarized in Figure 11.

So far, this is the first model that behaves as expected, given the assumptions presented in subsection 2.1. Both yes share at t1 and turnout at t1 have a positive effect on turnout at t2. The effect of turnout at t1 is rather strong, with an increase of around 0.062 in turnout at t 2 with one standard deviation increase in turnout at $t 1,0.10$. The effect of yes share at $t 1$ is small, around 0.006 on average, but it is consistently positive. Municipality size as a small negative effect.

Overall, the two 2013 multilevel models show a mixed picture. The model with yes share at $\mathrm{t} 2$ once again shows the unexpected results of a negative, albeit small effect of turnout at $\mathrm{t} 1$. The model with turnout at $\mathrm{t} 2 \mathrm{as}$ the response variable, on the other hand, produces estimates compatible with the assumption of a mobilization cascade. 
Figure 10: Parameter estimates for the 2013 multilevel model with yes share at t2 as the response variable.
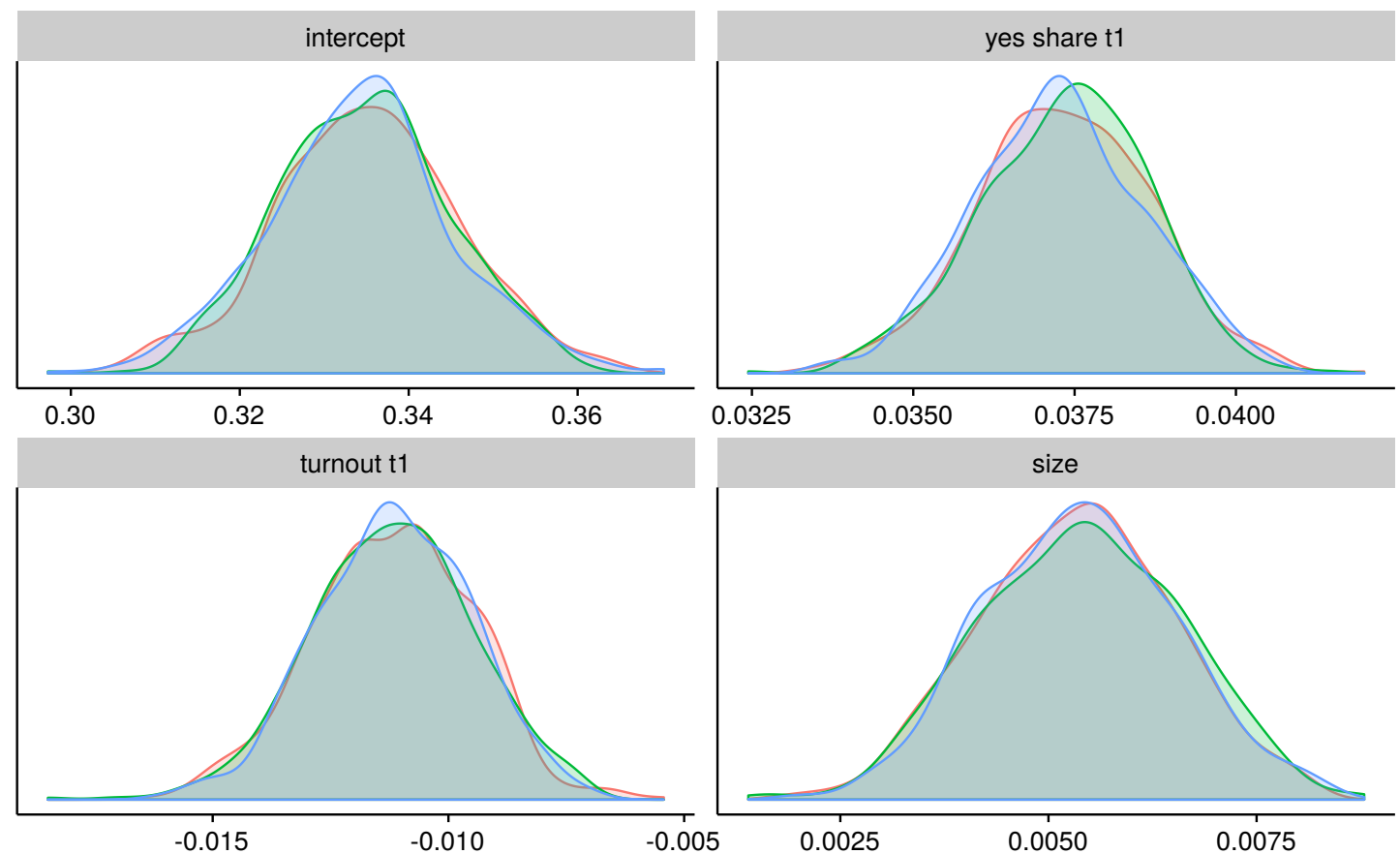

The different colors represent the three sampling chains.

\subsection{Parameter estimates for the 2014 initiative pair}

As is the case for the 2012 and 2013 initiative pair, the multilevel models for the 2014 initiative pair outperformed the single-level models. Therefore, in this section, the parameter estimates for the two multilevel models are presented. First, the estimates for the 2014 multilevel model with yes share at $\mathrm{t} 2$ as the response variable are summarized in Figure 12 .

The picture from the 2012 and 2013 multilevel models with yes share at t2 as the response variable is repeated in the 2014 model: Yes share at t1 has a strong positive effect of around 0.063 , whereas turnout at t1 has a small negative effect of around -0.003 , on average. Municipality size has, on average, a small positive effect, but a sizeable part of the distribution lies below 0 , so the effect is not consistent.

The estimates for the 2014 multilevel model with turnout at t 2 as the response variable are summarized in Figure 13.

The estimates for the 2014 model with turnout at t2 as the response variable 
Figure 11: Parameter estimates for the 2013 multilevel model with turnout at t2 as the response variable.
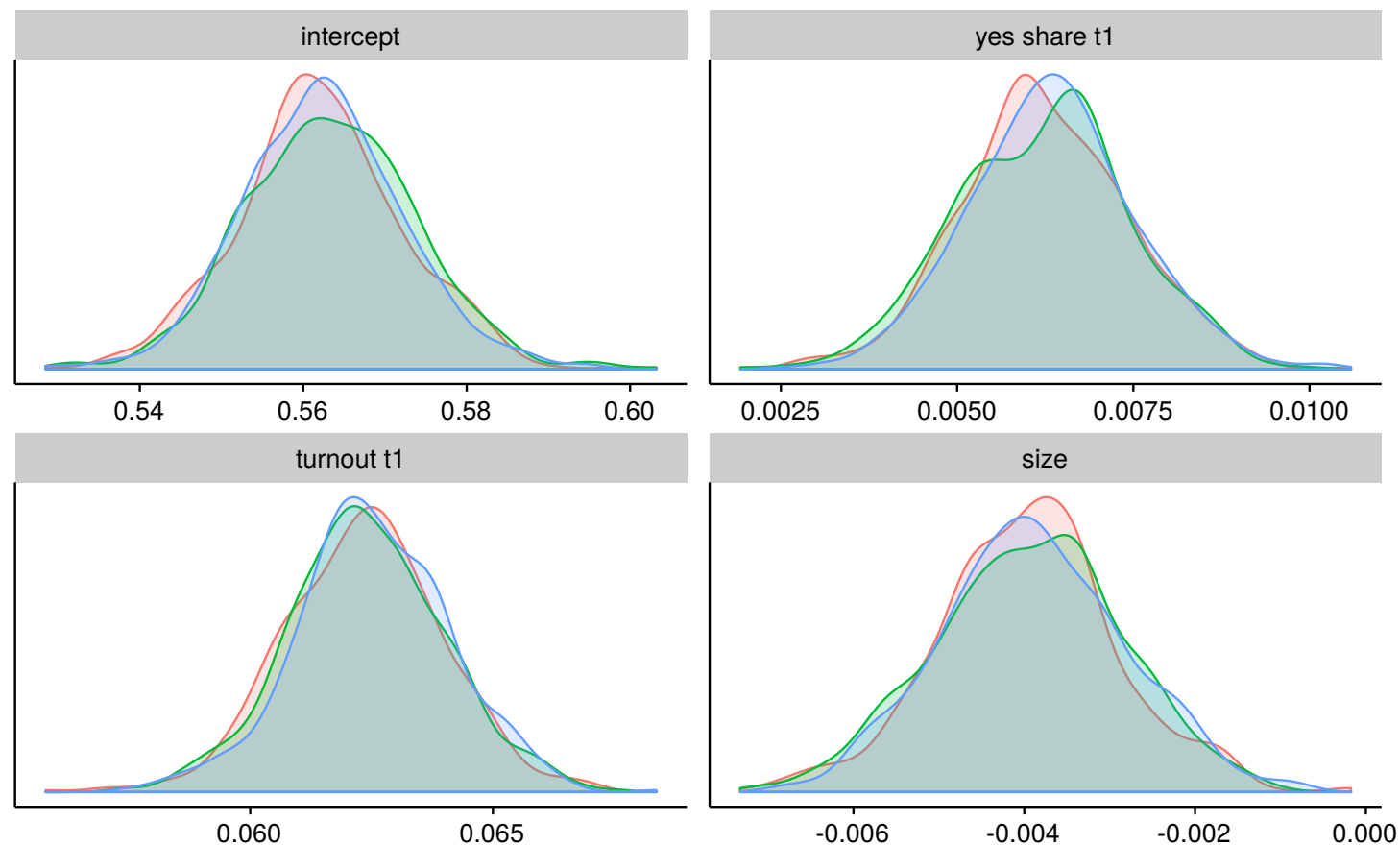

The different colors represent the three sampling chains.

resemble the results for the 2012 model. Yes share at t 1 has a fairly strong negative effect of around -0.024 per one standard deviation increase of 0.11 . Turnout at t1, on the other hand, has a strong positive effect of around 0.051 per one standard deviation increase of 0.07 .

Overall, the estimates for both multilevel models of 2014 are partly unexpected given the assumptions laid out in subsection 2.1. Given the idea of a mobilization cascade, the effects of yes share at $\mathrm{t} 1$ and of turnout at t1 should have been only positive, but they are not.

\section{Discussion}

I have described five empirical assumptions that should hold if the mobilization cascade was real. The first of those assumptions is that the probability to vote yes in the first initiative in an initiative pair has a positive impact on the probability to 
Figure 12: Parameter estimates for the 2014 multilevel model with yes share at t2 as the response variable.
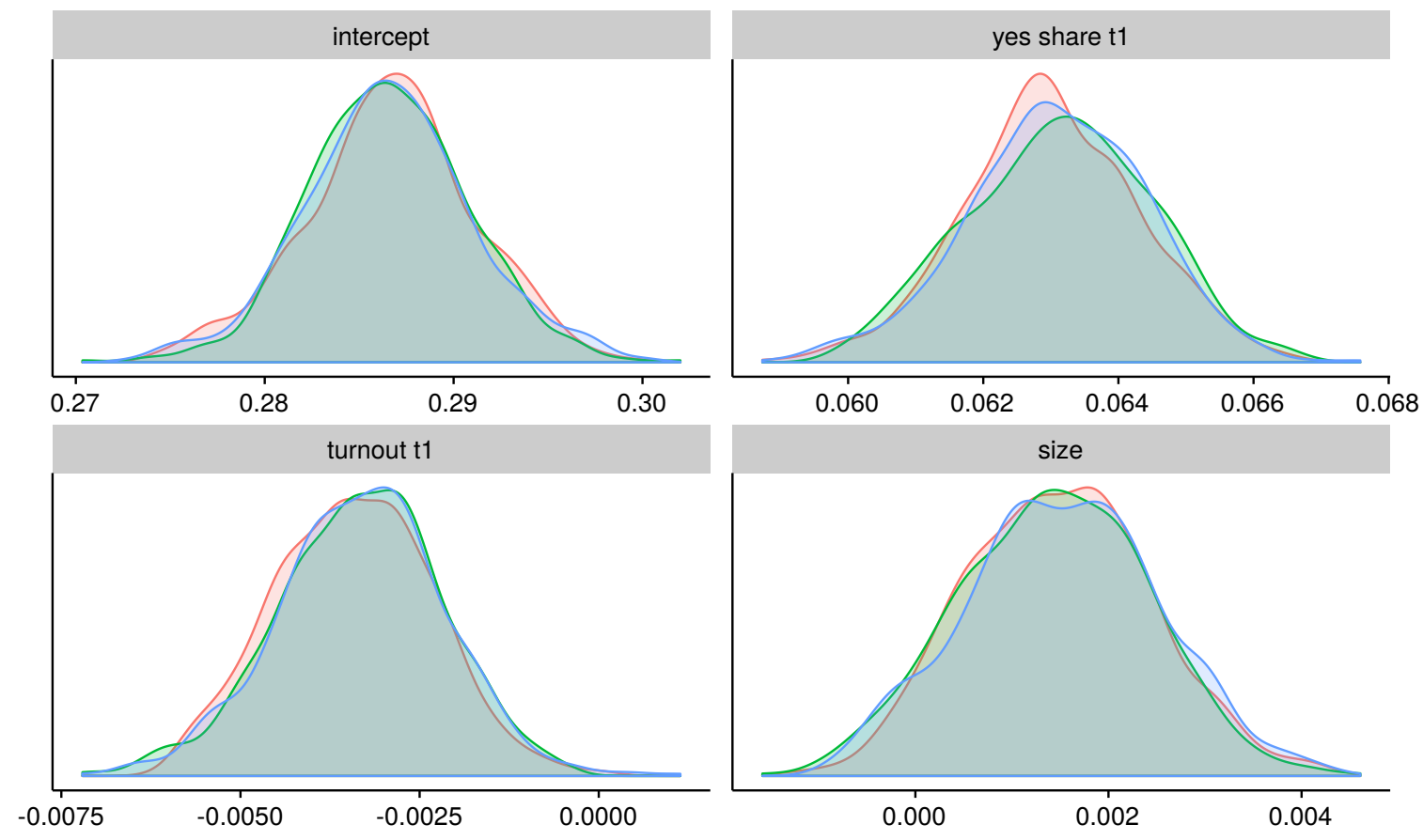

The different colors represent the three sampling chains.

vote yes in the second initiative. The results support this assumption: In the 2012, 2013 and 2014 multilevel models with yes share at t2 as the response variable, yes share at $\mathrm{t} 1$ has a strong, positive impact.

The second assumption about the mobilization cascade is that the probability to vote at all in the first initiative has a positive effect on the probability to vote at all in the second initiative. This assumption is also supported by the results: In all multilevel models with turnout at $\mathrm{t} 2$ as the response variable, turnout at t 1 has a strong positive impact.

The third assumption about the mobilization cascade is that the probability to vote yes in the first initiative has a positive effect the probability to vote at all in the second initiative. This assumption is not supported by the results. Out of the three models with turnout at $\mathrm{t} 2$ as the response variables, only in one case does yes share at $\mathrm{t} 1$ positively affect turnout at $\mathrm{t} 2$ - in two out of three cases, yes share at $\mathrm{t} 1$ has a small, but consistent negative effect.

The fourth assumption about the mobilization cascade is that the probability 
Figure 13: Parameter estimates for the 2014 multilevel model with turnout at t2 as the response variable.
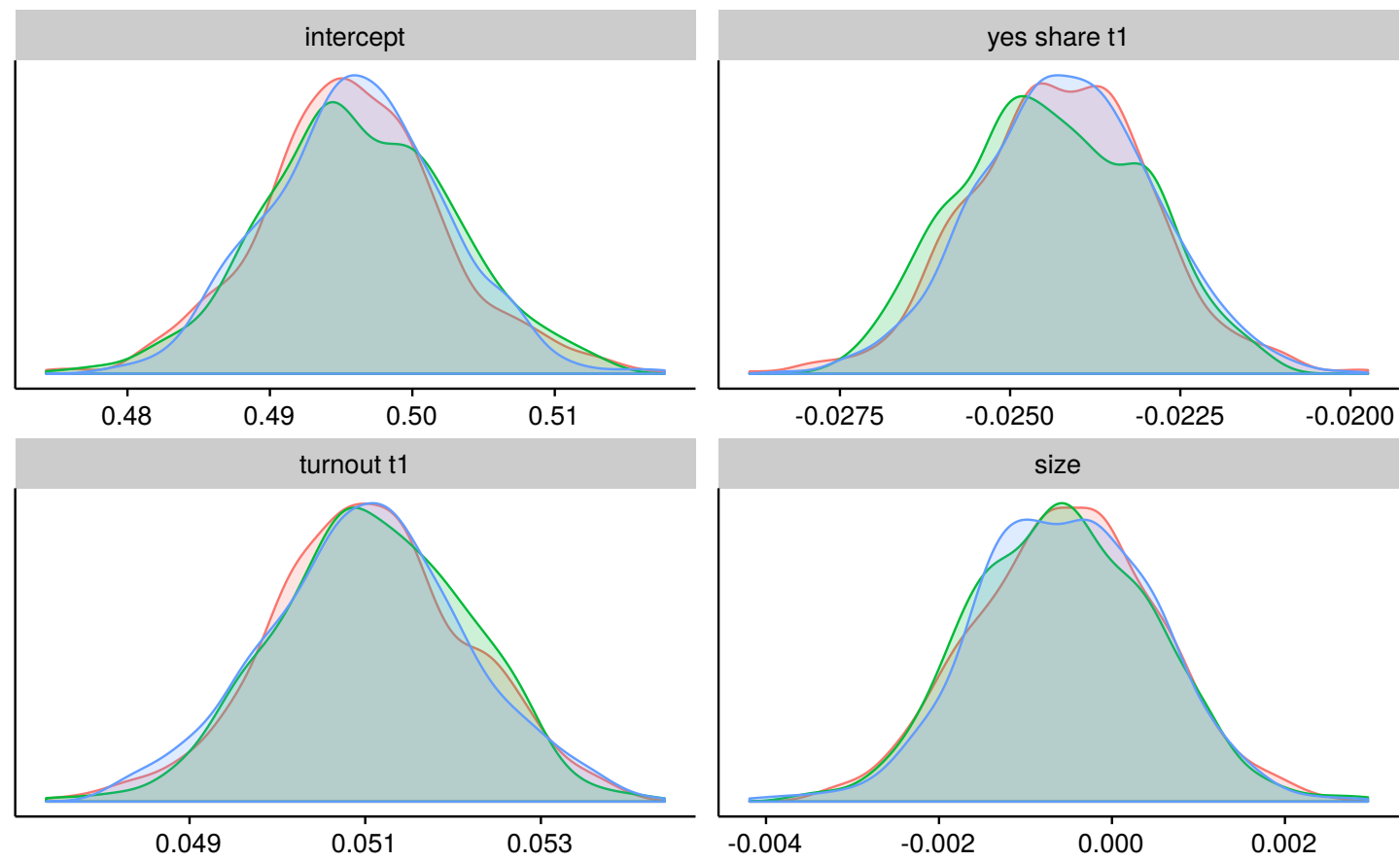

The different colors represent the three sampling chains.

to vote at all in the first initiative has a positive effect on the probability to vote yes in the second initiative. This assumption is also not supported by the results. In all three models with yes share at $\mathrm{t} 2$ as the response variables, turnout at $\mathrm{t} 1$ has a small, but consistent negative effect.

The fifth and final assumption about the mobilization cascade is that the Simpson's paradox should not be present, in the sense that multilevel models should perform at least as well as single-level models. This assumption is supported by the results: For every initiative pair, the multilevel models outperformed the single-level models, both for the model with yes share at t2 as the response variable and the model with turnout at t2 as the response variable.

\subsection{What remains of the mobilization cascade?}

Only three of the five assumption about the mobilization cascade are supported by the results. This means that, if the mobilization cascade exists, it is a weaker 
effect than originally assumed. The assumption that turnout at t1 should positively impact yes share at $\mathrm{t} 2$ and the assumption that yes share at $\mathrm{t} 2$ should positively impact turnout at $\mathrm{t} 2$ are an important part of the concept of the mobilization cascade, but the opposite of those assumptions can be observed: Turnout at t1 leads to a slightly lower yes share at t2 (in three out of three cases), and yes share at $\mathrm{t} 1$ leads to slightly lower turnout at t2 (in two out of three cases). These results actually suggest a demobilization effect, not a mobilization effect.

What do these findings imply for the mobilization cascade? At least three logical configurations are possible. First, there is no mobilization cascade at all. Second, there is a mobilization cascade, but it not a comprehensive effect, as evidenced by the presence of a demobilization effect. Third, the demobilizing effect is noise, and the mobilization cascade is a strong and comprehensive effect. The third possibility seems clearly wrong. Between the first and second possibilities, the second seems best to describe the overall findings: A mobilization cascade cannot be ruled out, but it is not the only mobilizing effect present.

It is worth mentioning that the results are not identical for all initiative pairs. This could further chip away at the idea of a strong and consistent mobilization cascade in that the nature of the political issues at hand matters - some issues might have more mobilizing (and demobilizing) potential than others. One possible theoretical appreciation of such differing mobilizing potential of issues is offered in the agenda-setting literature with the concept of issue obtrusiveness [45, 46, 47]: Issues that are more immediately intuitive and relevant to citizens in their everyday lives have a higher chance of becoming salient than abstract issues removed from everyday life. In the context of the initiative pairs analyzed in this study, the 2014 initiative pair is perhaps an example of an obtrusive issue, because both initiatives deal with immigration, a typical obtrusive issue. As it happens, the demobilizing effects are strongest in the 2014 initiative pair.

\subsection{Limitations of the present study}

This study is exploratory in nature, and therefore, its conclusions are tentative at best. The biggest limitation of this study is that limitation of the data analysis to only aggregated municipal data. In order to explore the question of mobilization cascades more thoroughly, additional research on the micro level is necessary. This could be done with survey-type research, with experimental data, or, ideally, with exit polling.

Furthermore, the present study is somewhat myopic in scope. I only analyze initiative pairs in Switzerland, but the ultimately truly relevant questions are, first, whether mobilization cascades might be a feature of contemporary direct democracy in general and not just of local Swiss direct democracy, and, second, whether the mechanism of the mobilization cascade is present in voting behavior beyond direct 
democratic procedures. Since I understand the concept of the moblization cascade to stem from the general nature of human cognition, the phenomenon of the mobilization cascade, if it were a real and detectable effect, should exist outside of direct democratic contexts.

\subsection{Normative implications}

The empirical study of direct democratic procedures is incomplete without a short reflection on the normative implications of the results, because the general normative status of direct democracy is controversial, mainly for two reasons. First, direct democratic procedures are more likely to be used to further interest group preferences than to further the preferences of ordinary citizens [48, 49, 50]. Second, direct democracy as a proceduralist institution holds the potential to override important normative aspects of democracy, such as minority rights $[51,52,53,54$, 55].

Mobilization cascades could be normatively problematic for a reason that is neither directly related to interest group influence nor to the threat to minority rights. By means of mobilization cascades, voters could become gradually more accepting of more radical ideas by what is, in essence, a process or irrational salience generation. The fact that voters might become more accepting of more radical ideas is not, in and of itself, a normative problem, because the radicality of a political demand cannot be deemed a normative problem eo ipso. For example, some time ago, the demand to abolish slavery was very radical. However, we wouldn't deem the abolishment of slavery normatively irrational or problematic simply because it was, at one historical point in time, radical (in the sense of proposing a categorical change to the status quo).

The potential normative problem with mobilization cascades is more subtle. In an initiative pair, voters have the chance to express their preference on an issue twice in a row. In a hypothetical situation, voters might express their overall approval of a ballot measure; by giving the ballot measure a majority of yes votes, voters express that they prefer $A$ to $\neg A$. Now, in this hypothetical situation, the voters get the chance to cast a vote some time in the future on ballot measure $B$. Ballot measure $B$ deals with the same issue as ballot measure $A$, but it makes more far-reaching, more radical demands. If preferences were fixed, ballot measure $B$ would either pass or get rejected because the median voter either prefers $A$ to $B$ or $B$ to $A$. However, if voter preferences aren't fixed but are, as assumed by the mechanism of the mobilization cascade, shaped in part by the fact that there was a ballot measure on the same issue in the recent past, the general problem of cyclical preferences, or, more specifically, of Arrow's impossibility theorem [56] in direct democracy [48, 57], becomes more pronounced. Not only does the median voter have a set of preferences that might be cyclical, but the preference order is 
not fixed but shaped by real-world exposure to policy options at the ballot.

The potential normative problem with mobilization cascades, therefore, lies in its preference altering effect. This is a subtle, but potentially real problem. Of course, the preferences of voters have to have some sort of origin. The normative problem with mobiliation cascades is not that voters potentially change their opinion in general. Rather, the problem lies in the idea that the mere occasion of expressing one's preference order could alter that very preference order. Direct democratic decision-making is supposed to reflect the "honest" preferences of the voters. However, if those preferences are not endogeneous to the voters but are instead unwittingly shaped by the exogeneous mechanism of conducting direct democratic decision-making processes, the whole direct-democratic affair becomes, in principle, somewhat circular.

How much of an actual normative problem is this potential normative problem given the empirical results? The data analysis suggests that mobilization cascades might exist, but they are quite probably not strong effects. Consequently, the actual normative problem of mobilization cascades exacerbating Arrow's impossibility theorem should not be overstated. This normative question does, however, warrant future scientific attention. 


\section{References}

[1] David Altman. Direct Democracy Worldwide. Cambridge University Press, Dec. 2010 (cit. on p. 1).

[2] Jean-Jacques Rousseau. Du contract social, ou, Principes du droit politique. Amsterdam: Marc-Michel Rey, 1762 (cit. on p. 1).

[3] Maija Setälä. "Referendums in Western Europe - A Wave of Direct Democracy?" In: Scandinavian Political Studies 22.4 (1999), pp. 327-340. DOI: 10.1111/1467-9477.00022 (cit. on p. 1).

[4] International IDEA. Direct Democracy: The International IDEA Handbook. Stockholm, Sweden: International Idea, Apr. 2009 (cit. on p. 2).

[5] Ellen Immergut. "The Rules of the Game: The logic of health policy-making in France, Switzerland, and Sweden". In: Structuring politics. Ed. by Sven Steinmo, Kathleen Ann Thelen, and Frank Longstreth. Cambridge: Cambridge University Press, 1992, pp. 57-89 (cit. on p. 2).

[6] Herbert Obinger. "Federalism, Direct Democracy, and Welfare State Development in Switzerland". In: Journal of Public Policy 18.03 (1998), pp. 241-263. DOI: null (cit. on p. 2).

[7] Y. Papadopoulos. "How Does Direct Democracy Matter? The Impact of Referendum Votes upon Politics and Policy-Making". In: West European Politics 24.2 (Apr. 2001), pp. 35-58. DOI: $10.1080 / 01402380108425432$ (cit. on p. 2).

[8] Simon Hug and George Tsebelis. "Veto Players and Referendums Around the World". In: Journal of Theoretical Politics 14.4 (Oct. 2002), pp. 465-515. DOI: $10.1177 / 095169280201400404$ (cit. on p. 2).

[9] Gebhard Kirchgässner. "Direct democracy: obstacle to reform?" In: Constitutional Political Economy 19.2 (June 2008), pp. 81-93. DOI: 10.1007/s10602008-9039-3 (cit. on p. 2).

[10] David H. Everson. "The Effects of Initiatives on Voter Turnout: A Comparative State Analysis". In: The Western Political Quarterly 34.3 (Sept. 1981), pp. 415-425. DOI: $10.2307 / 447220$ (cit. on p. 4 ).

[11] David Magleby. Direct Legislation: Voting on Ballot Propositions in the United States. Baltimore: Johns Hopkins University Press, Nov. 2001 (cit. on p. 4).

[12] Caroline J. Tolbert, John A. Grummel, and Daniel A. Smith. "The Effects of Ballot Initiatives on Voter Turnout in the American States". In: American Politics Research 29.6 (Nov. 2001), pp. 625-648. DOI: $10.1177 /$ 1532673X01029006005 (cit. on p. 4). 
[13] Matt Childers and Mike Binder. "Engaged by the Initiative? How the Use of Citizen Initiatives Increases Voter Turnout". In: Political Research Quarterly 65.1 (Mar. 2012), pp. 93-103. DOI: 10.1177/1065912910388191 (cit. on p. 4).

[14] Caroline J. Tolbert and Daniel A. Smith. "The Educative Effects of Ballot Initiatives on Voter Turnout". In: American Politics Research 33.2 (Mar. 2005), pp. 283-309. DOI: 10.1177/1532673X04271904 (cit. on p. 4).

[15] Todd Donovan, Caroline J. Tolbert, and Daniel A. Smith. "Political Engagement, Mobilization, and Direct Democracy". In: Public Opinion Quarterly 73.1 (Mar. 2009), pp. 98-118. DOI: 10.1093/poq/nfp017 (cit. on p. 4).

[16] Caroline J. Tolbert, Daniel C. Bowen, and Todd Donovan. "Initiative Campaigns Direct Democracy and Voter Mobilization". In: American Politics Research 37.1 (Jan. 2009), pp. 155-192. DOI: 10.1177/1532673X08320185 (cit. on p. 4).

[17] Joshua J. Dyck and Nicholas R. Seabrook. "Mobilized by Direct Democracy: Short-Term Versus Long-Term Effects and the Geography of Turnout in Ballot Measure Elections". In: Social Science Quarterly 91.1 (2010), pp. 188-208. DOI: $10.1111 /$ j.1540-6237.2010.00688.x (cit. on pp. 4. 5).

[18] David Altman. "Does an Active Use of Mechanisms of Direct Democracy Impact Electoral Participation? Evidence from the U.S. States and the Swiss Cantons". In: Local Government Studies 39.6 (Dec. 2013), pp. 739-755. DOI: 10.1080/03003930.2012.679933 (cit. on p. 5).

[19] Markus Freitag. "Labor Schweiz: Vergleichende Wahlbeteiligungsforschung bei Kantonalen Parlamentswahlen". In: KZfSS Kölner Zeitschrift für Soziologie und Sozialpsychologie 57.4 (Dec. 2005), pp. 667-690. DOI: 10.1007/s11577005-0220-7 (cit. on p. 5).

[20] Markus Freitag and Isabelle Stadelmann-Steffen. "Stumbling block or stepping stone? The influence of direct democracy on individual participation in parliamentary elections". In: Electoral Studies. Special Symposium: Voters and Coalition Governments 29.3 (Sept. 2010), pp. 472-483. DOI: 10.1016/j. electstud.2010.04.009 (cit. on p. 5).

[21] Bernard R. Berelson, Paul F. Lazarsfeld, and William N. McPhee. Voting: A Study of Opinion Formation in a Presidential Campaign. Reprint edition. Chicago: University Of Chicago Press, June 1986 (cit. on p. 5).

[22] Larry M. Bartels. "Uninformed Votes: Information Effects in Presidential Elections". In: American Journal of Political Science 40.1 (Feb. 1996), pp. 194230. DOI: $10.2307 / 2111700$ (cit. on p. 5). 
[23] Jonathan St B. T. Evans. "Dual-Processing Accounts of Reasoning, Judgment, and Social Cognition". In: Annual Review of Psychology 59.1 (2008), pp. 255278. DOI: 10.1146/annurev .psych.59.103006.093629 (cit. on p. 5).

[24] Keith Frankish. "Dual-Process and Dual-System Theories of Reasoning". In: Philosophy Compass 5.10 (Oct. 2010), pp. 914-926. DOI: $10.1111 /$ j.1747$9991.2010 .00330 . x$ (cit. on p. 5).

[25] Arthur Lupia. "The Effect of Information on Voting Behavior and Electoral Outcomes: An Experimental Study of Direct Legislation". In: Public Choice 78.1 (Jan. 1994), pp. 65-86 (cit. on p. 5).

[26] Hanspeter Kriesi. "Role of The Political Elite in Swiss Direct-Democratic Votes". In: Party Politics 12.5 (Sept. 2006), pp. 599-622. DOI: $10.1177 /$ 1354068806066790 (cit. on p. 5).

[27] Shaun Bowler and Todd Donovan. "Information and Opinion Change on Ballot Propositions". In: Political Behavior 16.4 (1994), pp. 411-435 (cit. on p. 6.

[28] Georg Lutz. "Low turnout in direct democracy". In: Electoral Studies 26.3 (Sept. 2007), pp. 624-632. DOI: 10.1016/j.electstud.2006.10.008 (cit. on p. 6).

[29] Amos Tversky and Daniel Kahneman. "Judgment under Uncertainty: Heuristics and Biases". In: Science 185.4157 (Sept. 1974), pp. 1124-1131. DOI: 10.1126/science.185.4157.1124 (cit. on p. 6).

[30] Robert B. Zajonc. "ATTITUDINAL EFFECTS OF MERE EXPOSURE." In: Journal of Personality and Social Psychology 9.2, Pt.2 (1968), pp. 1-27. DOI: $10.1037 /$ h0025848 (cit. on p. 6).

[31] John A. Grummel. "Morality Politics, Direct Democracy, and Turnout". In: State Politics 83 Policy Quarterly 8.3 (Sept. 2008), pp. 282-292. DOI: 10.1177/153244000800800304 (cit. on p. 6).

[32] Daniel Biggers. Morality at the Ballot. Cambridge University Press, Nov. 2014 (cit. on p. 6).

[33] Daniel A. Smith, Matthew DeSantis, and Jason Kassel. "Same-Sex Marriage Ballot Measures and the 2004 Presidential Election". In: State $\&$ Local Government Review 38.2 (Jan. 2006), pp. 78-91 (cit. on p. 6).

[34] Jeremiah J. Garretson. "Changing with the Times The Spillover Effects of Same-Sex Marriage Ballot Measures on Presidential Elections". In: Political Research Quarterly 67.2 (June 2014), pp. 280-292. DOI: $10.1177 /$ 1065912914521897 (cit. on p. 6). 
[35] E. H. Simpson. "The Interpretation of Interaction in Contingency Tables". In: Journal of the Royal Statistical Society. Series B (Methodological) 13.2 (Jan. 1951), pp. 238-241 (cit. on p. 7).

[36] Jan Leighley. "Group Membership and the Mobilization of Political Participation". In: The Journal of Politics 58.02 (1996), pp. 447-463. DOI: 10.2307/2960234 (cit. on p. 8).

[37] JACK M. MCLEOD, DIETRAM A. SCHEUFELE, and PATRICIA MOY. "Community, Communication, and Participation: The Role of Mass Media and Interpersonal Discussion in Local Political Participation". In: Political Communication 16.3 (July 1999), pp. 315-336. DOI: 10.1080/105846099198659 (cit. on p. 8).

[38] Vivien Lowndes, Lawrence Pratchett, and Gerry Stoker. "Local Political Participation: The Impact of Rules-in-Use". In: Public Administration 84.3 (Aug. 2006), pp. 539-561. DOI: 10.1111/j.1467-9299.2006.00601.x (cit. on p. 8).

[39] Nicholas G. Polson and James G. Scott. "On the Half-Cauchy Prior for a Global Scale Parameter". In: Bayesian Analysis 7.4 (Dec. 2012), pp. 887-902. DOI: 10.1214/12-BA730 (cit. on p. 10).

[40] Bob Carpenter et al. "Stan: A Probabilistic Programming Language". In: Journal of Statistical Software 76.1 (2017), pp. 1-32. DOI: $10.18637 /$ jss v076.i01 (cit. on p. 11).

[41] R Core Team. R: A Language and Environment for Statistical Computing. Vienna, Austria, 2015 (cit. on p. 11).

[42] Andrew Gelman and Donald B. Rubin. "Inference from Iterative Simulation Using Multiple Sequences". In: Statistical Science 7.4 (Nov. 1992), pp. 457472. DOI: $10.1214 / \mathrm{ss} / 1177011136$ (cit. on p. 11).

[43] Andrew Gelman, Xiao-Li Meng, and Hal Stern. "Posterior predictive assessment of model fitness via realized discrepancies". In: Statistica Sinica 6.4 (1996), pp. 733-760 (cit. on p. 11).

[44] Aki Vehtari, Andrew Gelman, and Jonah Gabry. "Practical Bayesian model evaluation using leave-one-out cross-validation and WAIC". In: Statistics and Computing (Aug. 2016). DOI: 10.1007/s11222-016-9696-4 (cit. on p. 11).

[45] David Pearce Demers et al. "Issue Obtrusiveness and the Agenda-Setting Effects of National Network News". In: Communication Research 16.6 (Dec. 1989), pp. 793-812. DOI: 10.1177/009365089016006004 (cit. on p. 24). 
[46] Dan Drew and David Weaver. "Media Attention, Media Exposure, and Media Effects". In: Journalism \& Mass Communication Quarterly 67.4 (Dec. 1990), pp. 740-748. DOI: 10.1177/107769909006700428 (cit. on p. 24).

[47] Christine R. Ader. "A Longitudinal Study of Agenda Setting for the Issue of Environmental Pollution". In: Journalism \& Mass Communication Quarterly 72.2 (June 1995), pp. 300-311. DOI: 10.1177/107769909507200204 (cit. on p. 24).

[48] Sherman J. Clark. "A Populist Critique of Direct Democracy". In: Harvard Law Review 112.2 (1998), pp. 434-482. DOI: 10.2307/1342426 (cit. on p. 25).

[49] David S. Broder. Democracy Derailed: Initiative Campaigns and the Power of Money. 1 edition. New York: Mariner Books, Sept. 2001 (cit. on p. 25).

[50] Arthur Lupia and John G. Matsusaka. "DIRECT DEMOCRACY: New Approaches to Old Questions". In: Annual Review of Political Science 7.1 (2004), pp. 463-482. DOI: 10.1146/annurev .polisci.7.012003.104730 (cit. on p. 25).

[51] Lynn A. Baker. "Direct Democracy and Discrimination: A Public Choice Perspective". In: Chicago-Kent Law Review 67 (1991), p. 707 (cit. on p. 25).

[52] Donald P. Haider-Markel, Alana Querze, and Kara Lindaman. "Lose, Win, or Draw? A Reexamination of Direct Democracy and Minority Rights". In: Political Research Quarterly 60.2 (June 2007), pp. 304-314. DOI: 10.1177/ 1065912907301984 (cit. on p. 25.

[53] Erwin Chemerinsky. Challenging Direct Democracy. SSRN Scholarly Paper ID 1276471. Rochester, NY: Social Science Research Network, Sept. 2010 (cit. on p. 25).

[54] Marcel Stüssi. "Banning of Minarets: Addressing the Validity of a Controversial Swiss Popular Initiative". In: Religion 8 Human Rights 3.2 (Sept. 2008), pp. 135-153. DOI: 10.1163/187103208X347376 (cit. on p. 25).

[55] Jean-François Mayer. "A country without minarets: analysis of the background and meaning of the Swiss vote of 29 November 2009". In: Religion 41.1 (Mar. 2011), pp. 11-28. DOI: 10.1080/0048721X.2011.553140 (cit. on p. 25).

[56] Kenneth J. Arrow. "A Difficulty in the Concept of Social Welfare". In: Journal of Political Economy 58.4 (Aug. 1950), pp. 328-346 (cit. on p. 25).

[57] Maxwell L. Stearns. "Direct (Anti-) Democracy". In: George Washington Law Review 80 (2011), p. 311 (cit. on p. 25). 